\title{
UNA NOTA SOBRE EL GASTO DE TIMBRE DE CORREO A MEDIADOS DEL SIGLO XIX *
}

\author{
ANTONIO ROJAS FRIEND \\ y JUAN FRANCISCO FUENTES \\ Dpto. Historia Contemporanea \\ Universidad Autonoma de Madrid
}

Esta nota pretende ser una primera aproximacion a un material estadístico alternativo y complementario a los inventarios notariales post mortem, en los que, fundamentalmente, se han basado hasta ahora aquellos investigadores que se han ocupado de la difusión del libro en la España del siglo XIX. Se trata de los datos mensuales del gasto de timbre de correo publicados mensualmente por la Dirección General de Rentas Estancadas en las páginas de la Gaceta de Madrid entre los años 1850 y 1860 . Es una fuente bien conocida y ampliamente utilizada para el estudio de la difusión y las tiradas de la prensa española, y especialmente madrileña, cuyos datos de franqueo se recogen a lo largo de un periodo mucho más amplio que los referentes a la distribución postal de libros, folletos y otros impresos.

La información sobre el franqueo de periódicos e impresos figura por primera vez en el número de la Gaceta del 15 de mayo de 1850, y corresponde al mes de enero de ese mismo año. A partir de entonces, los datos seguirán apareciendo $\sin$ interrupción con periodicidad mensual, con pequeñas variaciones en el formato y el contenido del estadillo, hasta que a mediados de 1856 dejan de publicarse las cuentas sobre el franqueo de impresos. Sin embargo, el número del 25 de abril de 1861 publicará una amplisima información con los datos de Correos del año 1860, entre ellos los correspondientes a la distribución de impresos, lo que permite conocer, aunque de forma global y sin espe.

* Este trabajo forma parte del proyecto de investigación Pueblo y público en la España del siglo $X I X$ (1808-1874), financiado por la DGICYT (PS90-0040) y dirigido por J. F. Fuentes.

Revista de Habura lionomica

Año XIV, Inviemo $19 \%, \mathrm{~N} \div 1$ 


\section{GRÁFICO 1}

MEDIA MENSUAL DE FRANQUEO DE IMPRESOS (en reales)

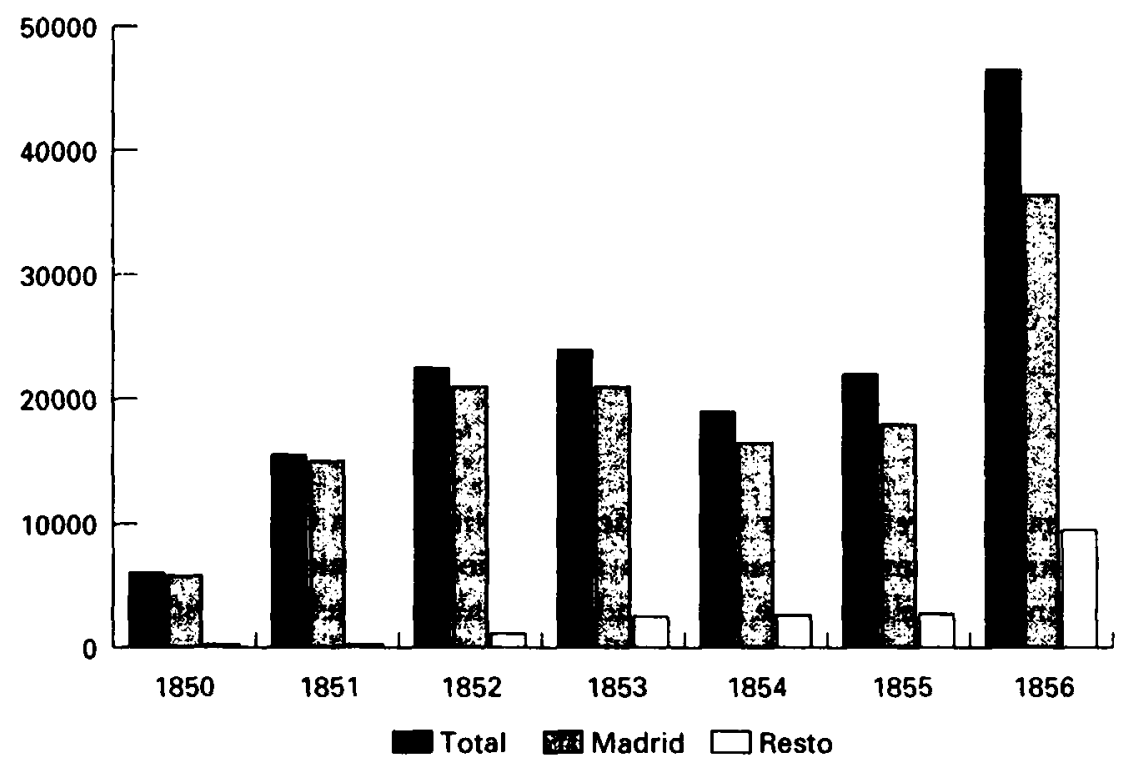

cificación de los titulos, el volumen de gasto postal generado por el negocio editorial al final de la década. Contamos, pues, con una exhaustiva serie estadistica llena de posibilidades para conocer la evolución, mes a mes, de la distribución y, a partir de ahi, de la demanda y de la producción editorial en la España de mediados del siglo XIX, en un periodo de rápida alternancia política entre el moderantismo y el progresismo y todavía en plena transición cultural entre el Antiguo y el Nuevo Régimen. Una transición que, según Jean-François Botrel (1988), en lo tocante a la industria editorial y a sus estructuras comerciales aún no habria concluido a finales del siglo xix.

Por lo pronto, la prensa periódica se beneficiaba de unas tarifas postales más favorables que las de los impresos: 40 reales por arroba frente a 50 de estos últimos hasta febrero de 1856 , fecha en que las tarifas se redujeron a 30 y 40 reales, respectivamente. No es seguro, sin embargo, que esta diferencia tarifaria, que parecia privilegiar la distribución de periódicos, explique la aportación notablemente inferior de los impresos al gasto de correo. En enero de 1850 el envio postal de periódicos supone 41.325 reales en franqueo, mientras que los impresos generan por el mismo concepto 2.283 reales, es decir, un 94,8 por 100 por un 5,2 por 100, sobre el total de ese mes. En los seis años siguientes, los continuos altibajos de las cifras no impiden que se aprecie una 
clara tendencia a la reducción de la diferencia porcentual entre ambas parti. das, que en enero de 1856 es del 78,7 por 100 frente al 22,3 por 100 , siempre a favor del timbre de periodicos. En conjunto, el gasto de franqueo ha experimentado en sólo seis años un incremento considerable: de los 43.608 reales pagados por ambos conceptos en enero de 1850 se pasa a 98.089 en el mismo mes de 1856. Un aumento que, en términos relativos, es mucho mayor en la partida de impresos, que en ese mismo período multiplica por 9,16 el importe pagado por franqueo. La tendencia se mantiene en los años siguientes. Aunque los estadillos de la Gaceta dejan a partir de 1856 de incluir los impresos, los datos globales del año 1860 arrojan una media mensual de 46.676 reales por este concepto, es decir, 20,4 veces más que en enero de 1850 .

El análisis de este material estadístico indica, pues, una adaptación relativamente rapida del impreso tradicional -el folleto y el libro, principalmente - a las exigencias del nuevo marco histórico, por más que su arranque sea algo más lento que el de la prensa. El incremento en la difusión postal de impresos se detecta, tal como muestran los gráficos II y III, en las dos variables posibles: en número de títulos y en gasto de franqueo, ambas cuantificadas en su media mensual para soslayar los meses que eventualmente omite la Gaceta -mayo, junio y julio de 1854 y abril y junio de 1855 - No son éstas las únicas deficiencias que presentan los listados de la Dirección General de Rentas Estancadas. En Madrid, por ejemplo, la amplia relación de títulos no se puede considerar completa, por cuanto las principales librerias de la capital - Hernando, Bailly y sobre todo Mellado, que llega a pagar más de dos mil reales al mes por derechos de timbre- no suelen dar referencia de las obras remitidas, sino simplemente el importe global. Por su parte, la Administración de Correos de Barcelona empieza a facilitar los titulos de los impresos en 1853. El manejo simultáneo de ambas variables - titulos y gasto- permite contrarrestar en parte estas carencias y mostrar con mayor fiabilidad, por tanto, la evolución del mercado editorial. Del gráfico III, realizado con este criterio, se desprenden algunas conclusiones interesantes, como es la confirmación del considerable incremento que experimenta entre 1850 y 1855 la distribución de impresos fuera del ámbito local, que podría situarse entre el 270 por $100 \mathrm{y}$ el 350 por 100, según se mida en número de titulos o en gasto de franqueo. En este último concepto, la subida a lo largo de la década llega a ser del 748 por 100: 74.829 reales en 1850 y 560.114 en 1860 .

Desde el punto de vista territorial, salta a la vista la enorme desproporción entre los impresos franqueados en Madrid y en provincias, con una diferencia que en 1850 es de 87 puntos porcentales de la capital sobre el resto de Espa. ña. También aqui resulta evidente la coincidencia básica entre la variable de 


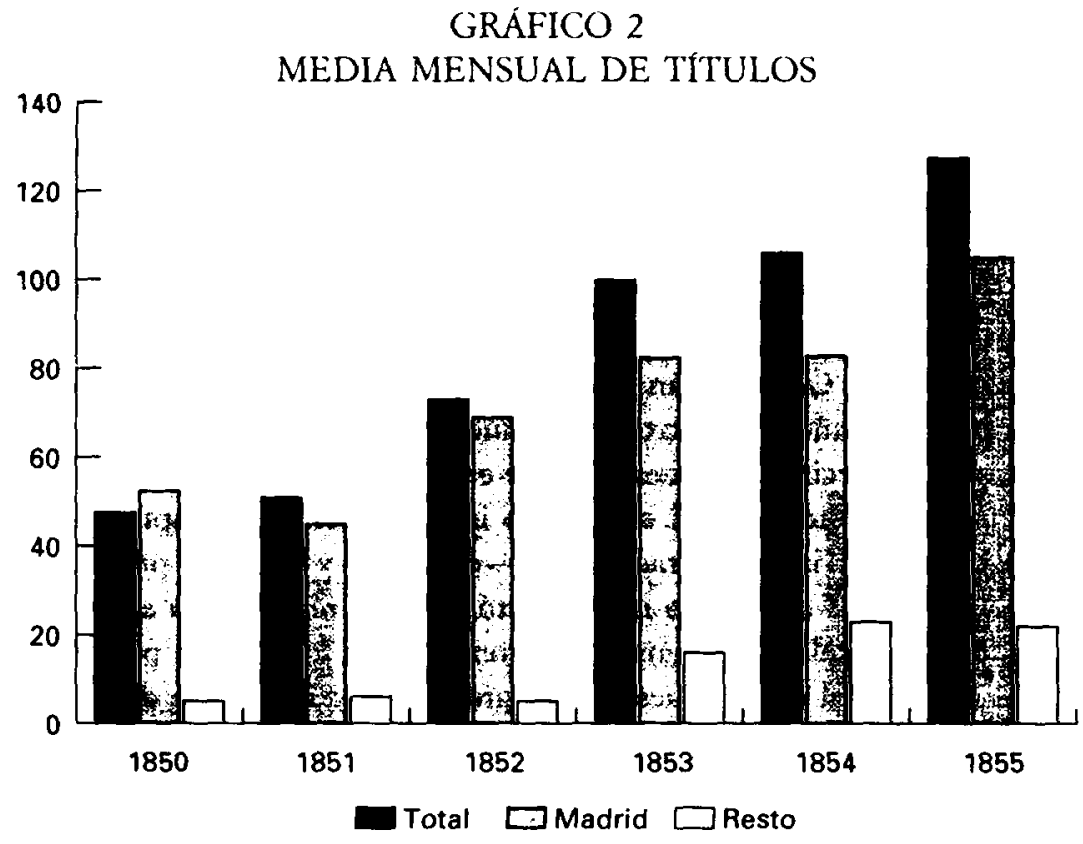

GRÁFICO 3

EVOLUCIÓN COMPARADA GASTO/TITTULOS $(1850=100)$

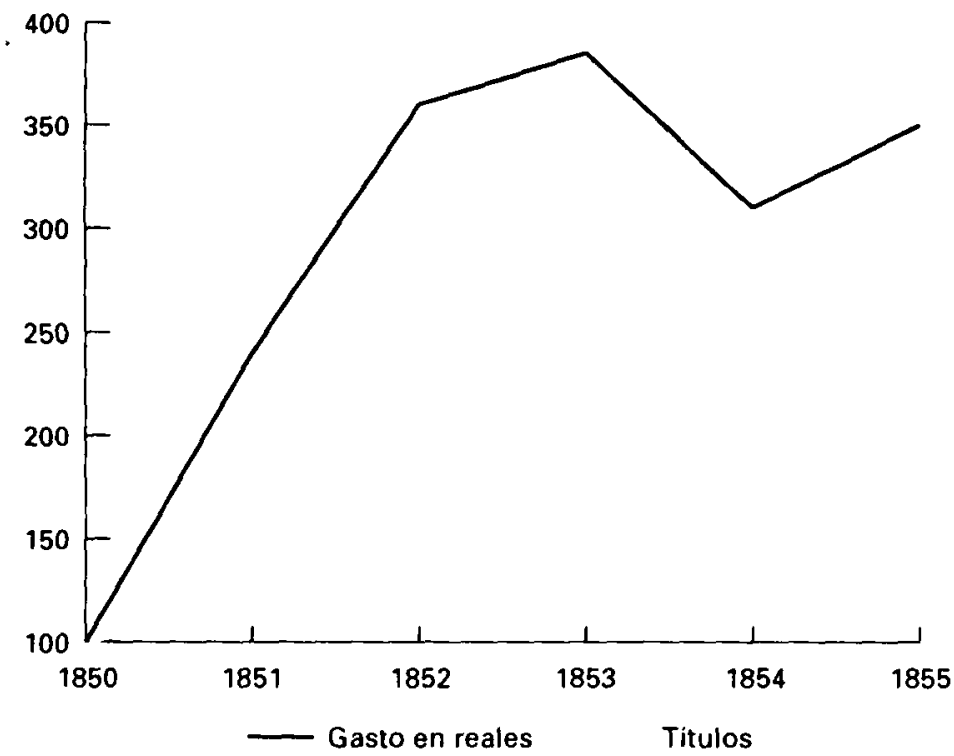


gasto y la cuantificación del número de titulos. Esta distancia entre Madrid y el resto se va recortando, sin embargo, en los años siguientes: en 1855, la ventaja de Madrid desciende a 68 puntos y en 1860 se ha reducido a 58 . Es de destacar, igualmente, el considerable progreso que registra la Administración de Correos de Barcelona en el franqueo de impresos, que pasa de tan sólo 875 reales en todo el año 1850 a 38.045 cinco años después y a 85.092 en 1860; un aumento, sin duda, excepcional, que parece reflejar el despegue de Barcelona como gran centro editorial.

Todo lo anterior nos lleva a formular algunas conclusiones, que en ciertos casos responden a una realidad claramente expresada en los gráficos y en otros no dejan de ser meras hipótesis esbozadas a partir de la extrapolación de datos muy fragmentarios:

1. Si hay un hecho incontestable es el extraordinario incremento registrado por la distribución postal de impresos entre 1850 y 1855 , que se puede cifrar en torno a un 300 por 100 , ya sea en número de títulos o en gasto de franqueo. La tendencia, como hemos visto, se mantiene en la segunda mitad de la década, para la que contamos únicamente con los datos globales de franqueo del año 1860 .

2. Tampoco ofrece dudas el enorme desfase que existe en la difusion postal de periódicos e impresos, en favor de los primeros, aunque en estos seis años la diferencia se recorte sensiblemente. El impreso tradicional parece mostrarse más torpe y más lento que el periódico a la hora de romper el ámbito estrictamente local y de abrirse a nuevos espacios y nuevos mercados. Bien es verdad que el desarrollo del mercado periodistico obedece en parte a motivaciones extraeconómicas y guarda una evidente relación con la coyuntura politica y en algún caso con el apoyo institucional que reciben algunas publicaciones, como los famosos boletines provinciales.

3. El fuerte incremento que se aprecia en la distribución de impresos a través de las Administraciones de Correos indica, más que un crecimiento proporcional de la producción, un rápido ensanchamiento del horizonte territorial del impreso clásico provocado por el aumento del consumo fuera del ámbito local. Un fenómeno de tal magnitud, pruducido en tan breve periodo de tiempo, sólo puede explicarse por la mayor fluidez y menor carestia del servicio de correos a partir de 1850 , elemento desencadenante de una expansión que empezó en la demanda y, probablemente, acabó impulsando un aumento de la oferta, tanto en el número de titulos editados como en la tirada media de las obras.

4. El abaratamiento de la distribución posibilitado por la modernización del servicio de correos se sumó al apogeo de la novela por entregas iniciado en los años cuarenta. La conquista por la cultura impresa de nuevos públicos y nuevos espacios - la «masificación de la lectura posible» de la que habla Bo- 


\section{GRÁFICO 4 \\ EVOLUCIÓN PORCENTUAL DEL FRANQUEO (Madrid/resto de España)}

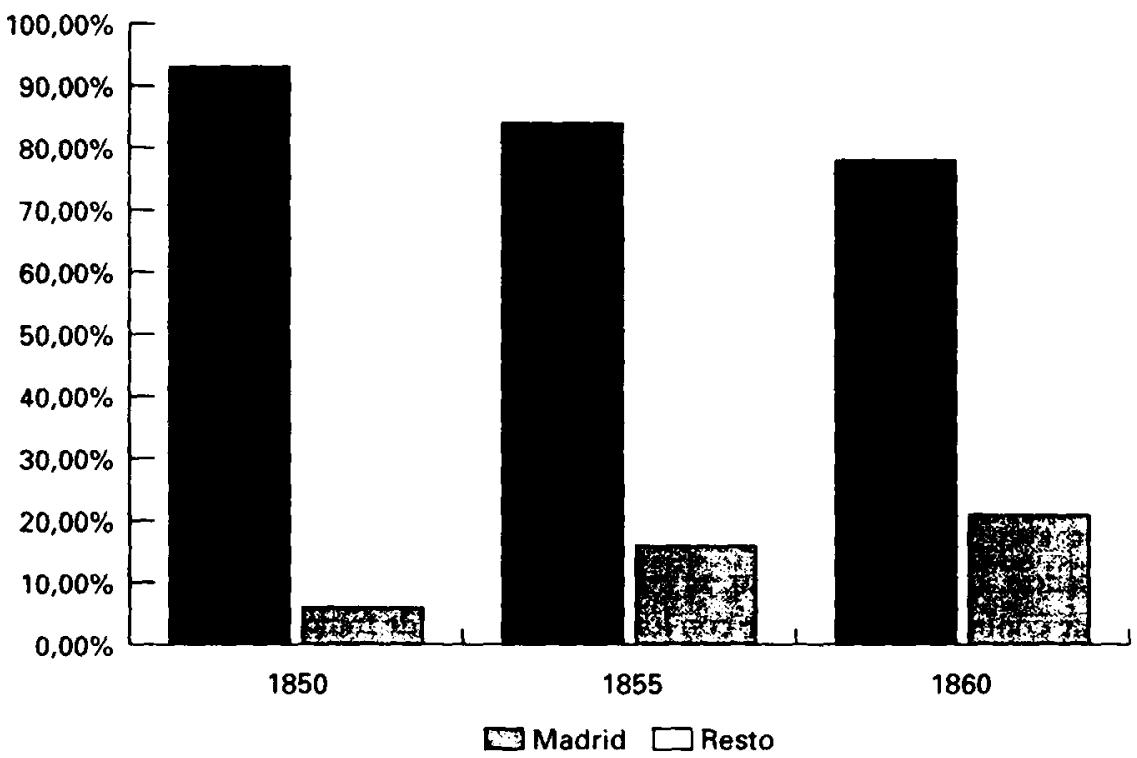

trel (1974) para esta época- propició una renovación de las prácticas comerciales y de la producción editorial, que llegó a ser espectacular en el caso de Barcelona.

A la postre, la prensa, el correo, muy pronto el ferrocarril y hasta los subgéneros literarios más modernos y populares actuaron, en un esfuerzo en gran medida fallido, como factores cohesionantes de la nación liberal: en la creación del mercado interior, en la vertebracion del territorio y en el desarrollo de una conciencia nacional, socialmente integradora. Lo apunta, a su manera castiza, don Benito Pérez Galdós al evocar el apogeo de las novelas por entregas:

En la novela de impresión y movimiento, destinada sólo a la distracción de cierta clase de personas, se ha hecho aqui cuanto habia que hacer, inundar la Peninsula de una plaga desastrosa, haciendo esas emisiones de papel impreso que son hoy la gran conquista del mercado español (cit. por Botrel, 1974, p. 151).

\section{BIBLIOGRAFIA}

BorRlı., Jean-François (1974): «La novela por entregas: unidad de creación y de consumom, en AA.VV: Creación y público en la literatura española, Madrid, Castalia, pp. 111-155. 
(1988): La diffusion du livre en Espagne (1868-1914), Madrid, Casa de Velázquez.

- (1993): Libros, prensa y lectura en la España del siglo XIX, Madrid, Fundación German Sánchez Ruipérez.

Cabrera, M.; Elorza, A.; Val.ero, J., y Vazqle: M. (1975): «Datos para un estudio cuantitativo de la prensa diaria madrileña (1850-1875)», en Prensa y sociedad en España (1820-1936), Madrid, Edicusa, pp. 47-147.

FIENTES, J. F. (1993): «La biblioteca del teniente general don José MacCrohon (Radiografia de un cambio cultural)», Boletin de la Real Academia de la Historia, CXC, pp. 235-282.

MartiNez Martin, Jesús A. (1992): Lectura y lectores en el Madrid del siglo Xix, Madrid, CSIC.

SANCHEZ-Alborioz, Nicolás (1975): «La progresión de la comunicación postal», Jalones de la modernización de España, Barcelona, Ariel, pp. 87-97. 